\title{
SENTENCING STRUCTURE: ITS EFFECT UPON SYSTEMS FOR THE ADMINISTRATION OF CRIMINAL JUSTICE
}

\author{
LLOYD E. OHLIN* \\ Frank J. Remington $\dagger$
}

I

The Evaluation of Aiternative Sentencing Structures

The formulation of a sound sentencing structure requires the resolution of a number of basic issues. ${ }^{1}$ Where ought responsibility for the sentencing decision be vested? What alternative types of disposition ought to be made available to the agency given responsibility? What limitations should be placed upon the severity of the sentence, particularly the length of incarceration? And finally, what criteria ought to guide or control the sentencing decision? ${ }^{2}$

These issues are not easily resolved. Adequate resolution requires agreement as to the principal objectives of a sound sentencing plan and a method of insuring that administration will be oriented toward the achievement of those objectives. Typical analyses of proposals for change in sentencing structure have been preoccupied with objectives and have consistently failed to produce a basis for predicting the impact of the sentencing proposal upon the day-to-day administration of criminal justice. As a consequence, administrative distortions occur which are unanticipated and, therefore, not controlled.

- A.B. 1940, Brown University; M.A. I942, Indiana University; Ph.D. 1954, University of Chicago. Professor of Sociology, New York School of Social Work, Columbia University. Sociologist, Illinois Parole and Pardon Board, 1947-53; special research study for Human Resources Research Office in Korea on problems of prisoner-of-war camps, 1953; Director, Center for Education and Research in Corrections, University of Chicago, 1953-56; Consultant, Office of the Sheriff, Cook County, Ill., 1955; Consultant, Survey of the Administration of Criminal Justice in the United States, American Bar Foundation, 1955-56. Author, Selection for Parole (i95I), Sociology and the Field of Corrections (1956). Contributor to sociological and legal publications.

† B.S. I947, LL.B. I949, University of Wisconsin. Professor of Law, University of Wisconsin; Special Consultant and Member, American Law Institute Model Penal Code; Director of Field Research, Survey of the Administration of Criminal Justice in the United States, American Bar Foundation; Member, Technical Staff and Advisory Committee, Wisconsin Criminal Code. Contributor to legal publications.

1 Two distinguished organizations, the American Law Institute and the National Probation and Parole Association, are now in the process of formulating sentencing proposals, but considerable disagreement exists between them. Compare the American Law Institute's MOdel PeNar Code $\$ \$ 6.06,6.07$ (Tent. Draft. No. 2, 1954), with Rubin, Long Prison Terms and the Form of Sentence, 2 N.P.P.A.J. 337 (1956), and Rector, Sentencing and Correction, id. at 352. For a more extensive exposition and analysis of these polar positions, see Tappan, Sentencing under the Model Penal Code, infra p. 528, and Turnbladh, A Critique of the Model Penal Code Sentencing Proposals, infra p. 544.

${ }^{2}$ There is some disagreement as to whether the legislature should seek to control sentencing and other correctional decisions. Model Penal Code $\$ \$ 7.01 \% 4$ ('Tent. Draft No. 2, 1954) views mandatory legislative criteria as essential with respect to probation, fine, and imprisonment. Others protest, however, that such criteria ought only to be advisory in light of our present imperfect knowledge in this area. 
All agencies engaged in the administration of criminal justice must direct their efforts toward the common objective of processing criminal offenders. This, of necessity, requires a degree of integration among their policies and practices. This practical operating equilibrium will inevitably be affected by a major change in the system. For example, a major change in the allocation of responsibility and discretion for sentencing will affect all agencies. The offender who anticipates a high mandatory sentence will resist arrest and conviction as certainly as he will endeavor to avoid the imposition of sentence following conviction. The natural tendency, under these circumstances, therefore, is for the agencies of criminal justice administration to engage in various kinds of accommodative responses to a changed sentencing structure, so that they may continue to perform their customary tasks-of arrest and conviction, for example-with the usual expenditure of time, effort, and money. This may result in a failure to achieve the objectives of the sentencing structure, since those objectives may be regarded as less important than the maintenance of the current administrative equilibrium.

In proposing and evaluating reforms in sentence structure, it is, therefore, necessary to have sufficient knowledge of the administrative needs of a criminal justice system to be able to anticipate the kind of pressures that will be exerted upon the sentencing structure to serve those needs. Only then can methods be devised to meet these pressures in other ways-for example, by increasing personnel, budget, or training-and thus prevent distortion of its objectives. Typically, however, this knowledge is not demanded for two reasons: there is inadequate account taken of the actual functions of sentencing in the administration of criminal justice; and there is inadequate awareness of the fact that the administration of criminal justice is a single, total process and that, therefore, changing one important aspect may require substantial reorientation of the entire system.

The emphasis here will be upon the relation between the sentencing decision and the criminal justice system. Some efforts will first be made, however, to define the functions of sentencing.

\section{II}

\section{The Functions of Sentencing}

Sentencing proposals are usually evaluated in terms of their anticipated effect upon individual offenders and upon the community as a whole.

\section{A. Effect Upon the Offender}

All would agree that it is important to know what effect a sentencing structure will have upon the likely rehabilitation of individual offenders. ${ }^{3}$ Such disagreement

${ }^{3}$ See Morris and Turner, The Lawyer and Criminological Research, 44 VA. L. REv. 163 (1958), where one of the critical needs of criminological research is said to be to decide "which of the available methods of treatment work best with this type of offender. There are diverse purposes pursued in criminal sanctions, purposes relevant to the offender, to others inclined toward a similar crime, and to the community at large; but . . . a treatment method shall be tested by its efficacy in keeping the offender from committing a crime in the future. There is more to the problem than this, but this is clearly, one worthy and important purpose which is frequently decisive in the choice between possible sentences." 
as does exist relates rather to the extent to which a given sentencing structure does, in fact, contribute to rehabilitation and the extent to which the objective of rehabilitation outweighs other objectives of the penal system.

\section{B. Effect Upon the Community}

It is clear also that account must be taken of the effect which a sentencing structure will have upon the community. Here, again, there are differences in emphasis, complicated in this instance by a difficulty of definition. When one speaks of the effects of sentence upon the individual offender, it is clear to whom reference is being made. The difficulty is that the present state of knowledge in the behavioral sciences does not permit precise measurement or prediction of these effects. It is not so obvious, however, what is meant when one speaks of the effect of sentencing upon the community. Typically, a generalized concept of the community is used to express the need for deterrence and incapacitation and to describe the pressure for retribution. Perhaps resort to such a concept is inevitable, since it is seldom very clear precisely who needs to be deterred, who are potential victims, or who is exerting the pressure for retribution. But however appropriate the use of a generalized concept of the community may be in attempting to measure the need for deterrence and community reassurance, it is, in itself, inadequate as a basis for evaluating sentencing proposals, for it does not take into account the other functions of sentencing and, thus, does not afford a satisfactory standard for determining how sentencing will actually work in a going system for the administration of criminal justice.

There are, in fact, at least five important ways in which sentencing affects the community, some of which are too seldom made explicit.

\section{Deterrence of potential offenders}

This is a customarily-emphasized function of sentencing. Such disagreement as exists is one only of degree. Some regard the need for deterrence as being great enough to warrant a sentencing structure which provides for the imposition of minimum periods of incarceration. Others deny the necessity for minimum penalties, asserting that the need for general deterrence is adequately served by prompt detection and arrest.

\section{Protection of potential victims of crime by incapacitating dangerous offenders}

This is also a customarily-emphasized function of sentencing. It is, of course, clear that the release of a dangerous individual creates a threat of injury to members of the community. The difficulty, however, lies in assessing the need for prolonged incarceration and in balancing that need against the destructive experience inevitably inflicted upon a person who is incarcerated for a substantial period of time.

3. Maintenance of respect for legal norms and for the system of administering justice

This function of sentencing is less often stressed. Quite apart from the pressure for retribution in certain cases, however, there is the general need to maintain respect 
for the law and for the system by which it is administered. 4 Indeed, in certain cases, there may be no clearly-defined necessity for deterrence or community reassurance, and yet, there may be a felt need to reassert the validity of the particular legal norm as a proper goal for the community; and this may, in fact, constitute a considerable influence upon sentencing.

\section{Making reparation to the injured victim of crime}

Despite the fact that reparation is almost uniformly thought to be an appropriate consideration in individual cases, it is commonly thought to be quite inappropriate as a general criterion in sentencing. ${ }^{5}$ To say, then, that reparation is an important function of sentencing does not mean that it is an essential or even a desirable objective of a penal system. That is another question. The fact is, however, that it does exist as an important objective in most systems for the administration of criminal justice today. The assumption that it does not or should not exist does not lessen its impact upon day-to-day sentencing decisions. ${ }^{6}$

Pressure to compensate the victim of crime has primary significance in terms of the choice between probation and incarceration, since reparation is typically accomplished by requiring payment to be made as a condition of probation. ${ }^{7}$ This is not, therefore, often a critical factor in determining the length of incarceration, although a long, judicially-imposed prison term may be explicable as an effort to enforce a policy of reparation by letting it be known that refusal to make appropriate compensation will have serious consequences. It seems obvious that the matter of reparation will have a greater influence on sentencing where discretion is in the trial judge than where discretion is shifted to a treatment tribunal or the parole board, since the administrative agencies, because of their relative isolation from the victims of crime, are less likely to regard it as a valid objective of the penal system.

\section{Accomplishment of other "social engineering" objectives of the penal law}

It is often assumed that the sole objectives of the penal law are to prevent or control seriously-deviated and dangerous conduct; and perhaps this should be so. In fact, however, there are other objectives which must be taken into account if the sentencing process is to be fully understood. It is a fair generalization that resort

'See Mead, The Psychology of Punitive Justice, 23 AM. J. Socrolocy 577 (19r8).

${ }^{5}$ E.g., reparation is not mentioned in Moder Pensi Code $\$$ I.02( $x$ ) (Tent. Draft No. 2, 1954), which sets forth the general purposes of the provision governing the sentencing and treatment of offenders; it is listed, however, as an appropriate condition of probation. Id. $\$ 301 . \mathrm{I}(\mathrm{h})$.

- A similar problem exists in probation supervision, where collection of reparation and support are important objectives of day-to-day administration, but are generally rejected as appropriate general objectives for probation systems. The consequence is that reparation and support continue to be emphasized, but administrators generally feel that apologies should be made for this practice. See, e.g., Cohen, Twvilight Zones in Probation, 37 Crim. L. \& Criminology. 288 (1947).

${ }^{7}$ There are other ways of meeting the problem-e.g., by incarcerating offenders at night and releasing them to work during the day. Statutes authorizing this kind of program are becoming increasingly common. See, e.g., Wis. STAT. $\$ 56.08$ (I955); Yoder, Wisconsin Throws Them Out of lail, Saturday Evening Post, Feb. 4, 1956, p. 25. 
will be had to the penal law only when other less harsh methods are incapable of achieving desired results. One example will suffice. There is a great current need for a method of enforcing the obligation of a man to support his wife and children. For many reasons, the processes of the civil law are often inappropriate to this end. Support of family has, therefore, become one of the primary functions of the current administration of criminal justice, which takes this factor into account in sentencing decisions. Like reparation to the victim of crime, family support has become one of the primary inducements for the use of probation. The threat and occasional imposition of substantial periods of incarceration provides an inducement to comply with the condition of probation which requires the payment of support.

\section{III}

\section{Administrattve Characteristics Which Bear Importantly Uton Sentencing}

A more serious deficiency in analyzing sentencing solely in terms of its effect upon rehabilitation, general deterrence, and community reassurance is that it assumes that agencies of criminal justice administration view sentencing in relation to these factors and will, therefore, use them as appropriate criteria. In fact, however, this is true to only a limited extent. Other objectives, such as a relatively expedient, economical system of adjudication may be viewed as paramount. ${ }^{8}$ In consequence, certain types of sentencing structures may be distorted beyond recognition to serve administrative convenience. This possibility must be considered in evaluating the merits of alternative sentencing proposals.

Certain basic characteristics of criminal justice systems and of offenders have an important bearing upon the way sentencing structures are implemented.

\section{A. Minimum Requirements of Criminal Justice Systems}

Although there are infinite variations among systems for the administration of criminal justice, there is sufficient basic similarity to make possible some meaningful generalization. First, all systems must convict or acquit most serious offenders. Secondly, all systems must treat offenders in a generally-accepted way in relation to rehabilitation, deterrence, and community reassurance. Finally, all systems must accomplish these objectives within relatively narrow time, personnel, and budgetary limitations.

\section{B. Tactics of the Offender}

Most persons charged with crime are convicted and know they will be. The large majority, therefore, views the central issue in the administration of criminal justice

The best available analysis of how sentencing actually works in a given system for the administration of criminal justice is Newman, Pleading Guilty for Considerations: A Study of Bargain lustice, $46 \mathrm{~J}$. Crim. L., C. \& P. S. 780 (1956). Mr. Newman describes a system as it actually functions and also as it is viewed by lawyers, judges, and offenders who are processed thereby. The article is based upon Donard J. Newman, A Study of Informal Processes in Felony Convictions (unpublished thesis in University of Wisconsin Library 1954). 
to be the type and length of sentence, rather than conviction or acquittal..$^{9}$ Their primary effort is to cause their sentences to be as low as possible. The only generally available method they have for attaining this end is to make conviction difficult by pleading not guilty, demanding counsel, and perhaps a jury trial when a high sentence is anticipated, and to make conviction easy by pleading guilty when to do so will result in a lower sentence. ${ }^{10}$

C. Relation Between Sentencing and the Administrative Needs of the System

When a system is threatened by offenders' demanding full, formal adjudication of their cases, it faces the alternatives of either not adjudicating many serious offenders or requiring greatly increased staff and other facilities. The former is not possible; the latter probably unrealistic. Particularly is this so when there is a known way of conforming to currently-acceptable objectives, with a relatively modest expenditure of time and money. This can be done by operating the system in a way that will encourage a large number of pleas of guilty. Generally, this requires a willingness on the part of the agencies of criminal justice administration to make real or apparent sentencing concessions. ${ }^{11}$ This being so, it is obvious that these agencies may evaluate sentencing structures not primarily in terms of their suitability with regard to the objectives of rehabilitation, deterrence, and community reassurance, but rather in terms of whether they facilitate the principal task of maintaining a relatively expedient, economical system. There is sufficient variation among the way the police, the prosecutor, and the trial court view their primary function to warrant a brief description of each.

\section{Function of the police and its relation to sentencing ${ }^{12}$}

The average police officer is under terrific administrative pressure to clear known offenses by arrest and conviction. This pressure can be met short of influencing the sentence which may be imposed upon offenders following conviction, for police efficiency is measured largely in terms of offenses cleared by arrest and percentage of convictions. Accordingly, arrest and conviction have long since come to be considered the primary police objectives in handling offenders, and no systematic effort has been made to correlate successful police work with the type and length of sentence imposed, or even to keep information concerning sentences. The police-

\footnotetext{
"The question of the attitude of offenders toward sentencing and particularly "bargain justice" is most helpfully analyzed in Newman, supra note 8, at 783, where the typical attitude is described: "The outcome of the conviction process from the point of view of the offender is satisfactory or unsatisfactory depending upon the actual sentence he receives compared to his expectation of punishment at the time he is arrested."

${ }^{10}$ For an excellent presentation of many aspects of this problem, see ibid.

${ }^{11}$ See Newman, op. cit. supra note 8, at 220, where he concludes: "While informal bargaining processes may or may not be ethical, depending upon the reference point used, they are widely accepted as expedient by both lawyers and court, and their very expediency probably accounts for their devclopment."

. ${ }^{12}$ This section is based largely upon the perceptive comments of Herman Goldstein, who is associated with the Governmental Research Institute, in Hartford, Conn.
} 
man, therefore, is not likely to think of a sentence in relation to its appropriateness for the particular offender or to think explicitly about the effect of sentencing upon general deterrence or community reassurance.

Reinforcing this attitude is the fact, too, that in the large department, the number of offenders processed is so great that an individual police officer does not develop a continuing interest in specific offenders. The single exception is the highly-specialized unit which deals with specific kinds of offenses, such as those associated with narcotics, which are very serious in nature, where the investigation task is difficult, and where offenders are likely to be recidivists. Here, there may, indeed, be a specific police objective of lengthy incarceration, since the specialized unit may consider premature release of the offender back into the community as making more difficult their job.

Police may sometimes criticize lenient sentences given minor offenders. Often, however, this results not so much from dissatisfaction with the sentence imposed as from a desire to have the judge share some of the responsibility for a program of minimal enforcement, of routinely charging lesser offenses which can be summarily adjudicated, or of arresting but not prosecuting certain classes of offenders. It is a fair generalization rather to say that the police evaluate sentencing structures and practices primarily in relation to whether they facilitate or impede their principal crime-prevention task of arrest and conviction of offenders. More particularly, the basis of evaluation is whether sentencing serves as an inducement for offenders to admit the offense and plead guilty to the charge.

This emphasis is readily understandable. Most departments do not have manpower or facilities fully to investigate and present each case, and they would be severely handicapped if all or most cases were adjudicated by formal trial requiring the attendance of all police who participated in the preparation of the case. They operate on the hope and expectation that only a small minority of cases will require full adjudication.

\section{Function of the prosecutor and its relation to sentencing}

Although the prosecutor is more likely to assess the adequacy of a sentence in relation to the particular offender, it is, nonetheless, true that most urban prosecutors' offices assume that only a small minority of cases will have to be tried. If all cases had to be formally adjudicated, the size of the prosecutor's staff would have to be greatly increased. ${ }^{13}$ There is, consequently, strong pressure to operate the system in such a way as to induce most offenders to plead guilty, thus obviating the need for full preparation and presentation of most cases.

To induce pleas of guilty typically requires real or apparent sentencing concessions. If the judge has discretion and offenders believe that he is willing to give lighter sentences to those who plead guilty, there may be such pleas to "on-the-nose-

${ }^{13}$ See Note, Prosecutor's Discretion, 103 U. PA. L. Rev. 1057, 1070 (1955); Comment, The Influence of the Defendant's Plea on Judicial Determination of Sentence, 66 YALE L. J. 204, 205 (1956). 
charges" filed by the prosecutor. ${ }^{14}$ If, however, the judge does not have discretionas is the case where there is a fixed maximum term, for example-pressure may be exerted upon the prosecutor to make concessions by accepting a plea of guilty to a reduced charge carrying a lesser penalty. ${ }^{15}$

Since this practice, to some extent, relieves court congestion, the prosecutor may be expected to have the sympathetic understanding and support of the trial judge, who is not likely to be dissatisfied so long as he considers the sentence for the lesser offense to be adequate punishment for the conduct involved. In this assessment, he is likely to rely upon his understanding of the prevailing parole practice relating to time of release. For example, suppose the mandatory maximum term for armed robbery is ten years, the mandatory maximum term for unarmed robbery is five years, and armed robbers are usually paroled after having served four years. The trial judge in this situation will probably be quite satisfied with the reduction practice, since the offender will get out in four years whether convicted of armed or unarmed robbery, and he can be convicted of unarmed robbery without the time and expense of a trial. This assumes, of course, that the parole board will treat the case on its facts rather than according to the offense of which the person was convicted, although there is reason to believe that this may not necessarily be so.

\section{Function of the trial court and its relation to sentencing}

It is obvious that a trial court must consider adjudication its central responsibility. It is not so obvious, however, that it ought to consider sentencing less important. But if sentencing can be handled in such a way as to facilitate adjudication, this would be undesirable only if the concessions necessary to induce a high percentage of pleas of guilty were to result in a sentencing practice which did not meet the objectives of rehabilitation, deterrence, and community reassurance, as those objectives are conceived by the particular system. It is important for a trial judge to avoid court congestion, particularly of the criminal docket, for congestion may require longterm incarceration of some persons awaiting trial, an evil to be avoided even at the risk of other social hazards. ${ }^{10}$

The inducements offered by the trial court to plead guilty may vary. In some systems, an offender may be told the sentence he will receive if he pleads guilty, thus allowing him to decide in full possession of all of the facts. It seems likely that this can induce pleas of guilty, however, only if it is assumed that the consequence of a plea of not guilty will be a heavier sentence. A less obvious way is

\footnotetext{
14 This may explain the current practice in Philadelphia, where there is no reduction of charges in return for a plea of guilty. See Note, supra note 13, at rojo.

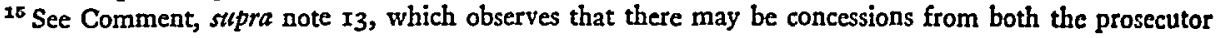
and the trial judge.

${ }^{10}$ Since the problem of calendar congestion is more serious in urban than in rural areas, the pressure to make concessions in the former is greater. This may account, in part, for the widely-recognized fact that sentences imposed by rural judges typically are more severe than those imposed by urban judges.
} 
the maintenance of a system where the common assumption of offenders is that a plea of guilty will result in sentencing concessions. And in this connection, many, if not most, judges make explicit their view that it is appropriate to reduce a sentence in return for a plea of guilty, because of the resultant contribution to the efficient and economical administration of the law..$^{17}$

\section{IV}

\section{Analysis of Illustrative Sentencing Structures in Terms of Their} Effect Upon Criminal Justice Administration

There is, of course, a wide range of alternatives concerning the allocation and sharing of responsibility for determining the length of incarceration. There is also great variation in systems for the administration of criminal justice. To illustrate the relationship between sentencing structure and the total administrative system, however, brief reference is made of two common sentencing variations.

\section{A. Legislatively-Fixed Maximum Term v. Judicially-Fixed Maximum Term}

Substantial disagreement exists as to whether a legislatively or a judicially-fixed maximum term is preferable. The current proposal of the American Law Institute provides for a legislatively-fixed maximum term which can be increased by the judge where the offender is a repeater, a professional, or seriously deviated. The current position of the National Probation and Parole Association opposes legislativelyfixed maximum terms and favors, instead, judicial discretion in the matter. ${ }^{18}$

The legislatively-fixed maximum term is said to have several important advantages. First, it affords the only means of achieving uniformity in sentencing. Secondly, it places responsibility for determining the time of the offender's release from incarceration in the parole board, where it should be. The trial judge is not wellequipped to make this decision, since it may require knowledge not then available, such as the nature of the offender's adjustment in the institution. Further, the parole board is a proper agency to balance the rehabilitative objective of early release under supervision and the community-security objective of prolonged incarceration of those who continue to pose a serious danger.

The judicially-fixed maximum term is urged, on the other hand, in the belief that sentences are now too high, that prolonged incarceration is inconsistent with

${ }^{27}$ See the tabulation of questionnaires sent to federal judges by the Yale Law Journal in Comment, supra note 13 , esp. at $219, \mathrm{n} .75$, where it is said that thirty-four of the judges contacted concur in this statement: "T make them a concession for pleading guilty for two reasons: (I) It saves the Government a great deal of time and money; (2) I believe it is in the best interests of saciety that criminal calendars be caught up as closely as possible, and by eliminating a great many trials the other defendants will obtain a more speedy trial." The editors conclude that the practice is undesirable, since it is not uniformly followed by judges and, therefore, results in a lack of unformity of sentences. The comment does not attempt to differentiate the replies of judges from busy (urban) districts from those of judges from districts with lighter calendars. It would be expected that considerations of court congestion would be stressed most by judges from the former districts.

${ }^{18}$ See note I supra. 
rehabilitation, and that it is, therefore, desirable to give the trial judge power to fix the maximum term, since this will generally result in lower sentences. ${ }^{10}$

Intelligent evaluation of these alternatives requires, among other things, an effort at systematic prediction of the likely impact of each upon existing administrative systems. This is particularly true of legislatively-fixed maximum terms, since the likely accommodative responses of agencies of criminal justice administration to this kind of feature may be such that the underlying policy objective will be frustrated in the process of implementation.

It was earlier pointed out that most offenders are primarily concerned with the matter of sentence-acquittal not being for most a realistic possibility-and, accordingly, they tend to bargain for sentencing concessions, threatening to insist upon formal adjudication if these are not made. Since most urban systems cannot afford fully to adjudicate all cases, this threat is usually effective, and concessions of two general kinds are made: where the judge has discretion, lighter sentences are given to those who plead guilty; where the judge does not have discretion, reduced charges are offered by the prosecutor to those who plead guilty.

Where the judge is given discretion in the matter of the maximum term and there is no high legislatively-fixed minimum term, pleas of guilty will be forthcoming if offenders assume that a guilty plea will result in a lighter sentence. This being so, a sentencing structure which places maximum discretion in the trial judge is easiest to implement administratively in general conformity with its objectives, provided that it is thought to be proper to give lighter sentences to those who plead guilty.$^{20}$ Many trial judges take the view that lighter sentences are warranted in the situation on the ground that the administration of justice is thereby facilitated. ${ }^{22}$ Others justify the practice on the ground that "a guilty plea demonstrates a readiness of the accused to accept responsibility for his criminal act"22 - but this seems to be little more than comforting rationalization. The dominant factor remains the need to expedite the administration of criminal justice, and the issue ought to be faced on that ground. ${ }^{23}$

${ }^{10}$ This system is employed for most crimes in a number of states. See, e.g., Wrs. Star, ce, 940-47 (1955).

${ }_{20}$ See Comment, stupra note 13 , at 206, where it is indicated that sixty-six per cent of the federal judges who returned questionnaires considered it appropriate to consider a plea of guilty as an appropriate basis for reducing sentence. See also NewMan, op. cit. supra note 8 , at 215 , where lawyers in a county studied were asked for their attitude toward "bargain justice." Sixty-four per cent favored it; only thirteen per cent thought it undesirable. Reasons given for favoring the practice was that it "seemed to work out equitably" and was a way of "speeding up justice." Those opposed, chiefly civil lawyers, thought it opened the door to political favoritism, corruption, and the like.

"II See note I7 supra.

${ }^{22}$ See Comment, supra note 13, at 209-xo, where it is pointed out that the fact that most offenders believe a plea of guilty will reduce their sentence means that this, rather than repentance, is probably the dominant factor inducing the plea.

${ }^{23}$ See id. at 2r9-20. Even where the judge has complete sentencing diseretion and where he takes account of a plea of guilty in determining the sentence, offenders may still, by the same token, attempt to obtain a reduced charge from the police and the prosecutor. When they succeed, concession is made at two stages; and this may be unfortunate if the judge is unaware of the earlier reduction in charge. It is, however, true that it is much easier for the police and the prosecutor to resist pressure to deal where 
Where the judge does not have this discretion, however, as where, for instance, the maximum term is legislatively-fixed, then concession in return for a plea of guilty must take a different form. ${ }^{24}$ Typically, it causes the police and the prosecutor to adopt a policy of accepting pleas of guilty to reduced charges. This, in effect, tends to shift discretion as to length of incarceration from the trial judge to the police and the prosecutor, not to the parole board, as may have been the objective of the sentencing structure. The extent to which the parole board is, in fact, deprived of discretion as to time of release depends upon the adequacy of the penalty for the lesser offense.

When the concession practice employed is reduction of the charge in return for a plea of guilty, it also inevitably follows that there will be some inconsistency between the offenses of which persons are convicted and their actual conduct. Of those who plead not guilty, most will be convicted of the offense charged. Some, mostly first offenders unaware of their bargaining strength, may plead guilty to the offense charged. Most, however, particularly experienced recidivists and persons with counsel, will successfully bargain for a reduced charge. Although the legislatively-fixed maximum may assure uniformity of sentence in relation to the offense for which the person is convicted, it does not necessarily insure consistency between the sentence and the actual conduct of the offender. The danger, therefore, arises that those who do not bargain may view the system as an unjust one, while those who successfully do so are likely to consider that justice has been done. ${ }^{25}$

In summary, then, the legislatively-fixed maximum term will create pressure on the police and the prosecutor to make sentencing concessions by accepting a plea of guilty to a lesser offense. This is so even if they can indicate to the offender the great likelihood of early parole release because, for example, of the pressure of institutional overcrowding; for most offenders are unwilling to run the risk that they will be the statistically unusual individual who is kept for the full maximum term. It would be possible, of course, for a system to evolve in which offenders assumed that a plea of guilty would be rewarded with early parole release, a plea of not guilty with late parole release. But this is not likely to happen for two reasons: First, a parole board is not likely to consider this an appropriate criterion for release.

the judge has complete discretion than it is when either or both the minimum or maximum terms is legislatively-fixed; for so long as it is assumed by offenders that a plea of guilty will be taken into account by the judge in sentencing, there will be inducement to so plead, even though the police and the prosecutor insist upon charging the offense which conforms most closely to the conduct of the offender.

24 Model Penal Code $\$$ 6.II (Tent. Draft No. 2, I954) gives to the judge the power to reduce a conviction to a lesser degree of felony or to a misdemeanor. The commentary makes it plain, however, that this power is to be exercised only when the penalty is unduly harsh as applied to the particular offender. It cannot properly be used as an inducement to plead guilty.

${ }^{25}$ See Newnssin, op. cit. supra note 8, at 212 , where a positive correlation is shown between bargaining success and the conception of justice as satisfactory. See also Newman, supra note 8, at 785: "Although all offenders recognized probation as their best break, of course, and many knew the possible length of sentence for their particular crime, recidivists knew customary sentences (and court district variations) for their offenses. In short, they recognized a 'good-as-compared-to-other-guys-I-know' sentence when they faced it." 
Secondly, the parole board is insulated from the difficulties which ensue when most offenders insist upon a formal trial-problems of investigation for the police, timeconsuming trials for the prosecutor, and congested calendars for the trial court. Accordingly, realistic appraisal of a sentencing structure containing legislatively-fixed maximum terms requires recognition of the fact that the achievement of its objectives may well require a willingness to support a considerably more expensive system of adjudication.

B. Legislatively-Fixed Minimum Term v. Judicially-Fixed or No Minimum Term

The formal objectives of a legislatively-fixed minimum term vary. A minimum term fixed at a year, as the American Law Institute proposes, is designed to give the penal institution sufficient time adequately to diagnose the offender. ${ }^{26}$ In some instances such as those covered by the many current statutes dealing with sale of narcotics, minimum terms are legislatively-fixed very high, with the apparent objective of deterring this highly dangerous conduct and incapacitating for a long period of time those who engage in it.

The effect which the legislatively-fixed minimum term will have upon the system for the administration of criminal justice will depend upon its length. A prescribed minimum term of one year is not likely to have great effect. Offenders are typically more concerned with the risk of being detained in prison for the period of a high fixed maximum term-even though parole practice may demonstrate that risk to be small-than they are with the certainty of having to remain in prison for a low fixed minimum one. Then, too, if all felonies routinely carry the same oneyear minimum term, there is no possibility of affecting the minimum period of incarceration by pleading guilty to a reduced charge. ${ }^{27}$ In short, the legislativelyfixed low minimum term presents no great problem in administrative implementation.

Quite the contrary is true, however, of the legislatively-fixed high minimum term, the effect of which is considerably greater than that of the legislatively-fixed high maximum term. The offender is typically unwilling to run the risk of serving a legislatively-fixed high maximum term, even though he is aware of the parole board's authority to release him well in advance of its expiration. Where there is a legislatively-fixed high minimum term, and, consequently, no prospect of ameliorative intervention by the parole board, the offender is certain to resist conviction by any means available to him. Moreover, agencies of criminal justice administration, such as the trial court, are inclined to resist the imposition of legislativelyfixed high minimum terms in cases where the penalty is believed to be dispropor-

${ }^{26}$ Moder Penat Code $\$ \$ 6.06,6.07$, and commentary at 24-26 (Tent. Draft No. 2, 1954).

${ }^{27}$ Where there is a low fixed minimum term, the primary effort of the offender is likely to be placed on probation rather than to be given a prison term. If he is to be incarcerated, the low minimum term is not, therefore, likely to be of concern, for he will expect to have to serve some minimum period of time, whether or not prescribed by statute. 
tionate to the conduct involved, ${ }^{28}$ and the likelihood of uniform application of the sanction, therefore, is extremely remote.

Statutes prescribing high minimum terms are not ignored. The possibility that they may be used, though remote, is sufficient to cause most sellers of narcotics, for example, willingly to admit guilt in return for the opportunity to plead guilty to a lesser offense of possession of narcotics or addiction. This considerably simplifies the task of the police and the prosecutor and reduces the number of narcotics cases which go to trial. Inadequate sentences do not, however, necessarily result, for the lesser offense of possession of narcotics typically allows for the imposition of a substantial prison term. A more serious question, again, is rather whether it is desirable to shift the sentencing discretion from the trial judge to the police and the prosecutor, for with a system where some offenses carry a legislatively-fixed high minimum term, the length of incarceration is greatly influenced by the choice of charge.

The consequences of the legislatively-fixed high minimum term are, thus, similar to the consequences of the legislatively-fixed maximum term. The difference lies in the fact that the legislatively-fixed maximum term has as its objective the placing of responsibility for determining the length of incarceration in the parole board, whereas the legislatively-fixed high minimum term has as its objective the denying of discretion as to the length of incarceration to any agency of criminal justice administration. The former is much more likely to be accomplished than the latter, for it requires only a willingness and an ability formally to adjudicate most cases; the latter requires as much, plus a willingness to impose penalties which are often believed to be inappropriate in the particular case in hand.

\section{$\mathrm{V}$ \\ Conclusion}

Adequate resolution of the difficult problems of sentencing requires continuing effort to decide and define the principal objectives of sentencing, particularly as they relate to rehabilitation of the individual offender and protection of the community. The decision as to objectives is not, of itself, enough, however, for objectives have meaning only to the extent that they are achieved by administrative implementation. Prediction of the likelihood of the achievement of objectives requires a basis for systematic evaluation of the impact of differing sentencing structures upon the total system for the administration of criminal justice. Ability to anticipate accommodative responses of the system will make it possible to provide controls which will prevent distortion of the sentencing structure to meet administrative needs.

${ }^{28} \mathrm{~A}$ judge's resistance may range in form from merely expressing his dissatisfaction to outright refusal to impose the mandatory penalty. The problem of administrative nullification of a mandatory sentence is not, of course, confined to mandatory maximum or minimum terms of imprisonment. The problem becomes increasingly important in the traffic field, where mandatory license revocation sanctions are increasingly common. These are often voided by judges where the penalty seems unduly severe, having in mind the nature of the offense and the person involved. 